\title{
Effect of extreme environmental temperature on the fracture resistance, and fatigue behavior of dual phase Ti-6Al-4V alloy
}

\author{
M. Islam ${ }^{1 *}$ F. Moon ${ }^{2}$, H. Aglan ${ }^{1}$ \\ ${ }^{1}$ Tuskegee University, Tuskegee, AL 36088, USA \\ ${ }^{2}$ Louisiana State University, Baton Rouge, LA 70803, USA
}

\begin{abstract}
The behavior of materials subjected to extreme environments is a challenging and diverse topic of interest to many researchers. Typically, structural materials in advanced energy systems are subjected to extreme heat, pressure, and radiation fluxes that may promote accelerated degradation. Titanium-based alloys are considered as favorable structural materials for diverse applications in such extreme environments, particularly in nuclear reactors, aerospace, and high temperature applications. In this work, the effect of extreme environmental temperature on the mechanical, fracture resistance, and fatigue behavior of dual phase Ti-6Al-4V alloy was investigated. Rectangular tensile specimens and single edge notched specimens of $75 \times 12.7 \times 0.81 \mathrm{~mm}$ were cut along the rolling direction and were exposed to environmental temperatures of $650{ }^{\circ} \mathrm{C}$, and $900{ }^{\circ} \mathrm{C}$ for two hours to simulate the extreme environmental conditions. The mechanical and fracture behavior of the materials exposed to these elevated temperatures were evaluated and the result revealed that the tensile strength and fracture toughness of the alloy was dropped significantly by $25 \%$, and $40 \%$, respectively after the exposure to $900{ }^{\circ} \mathrm{C}$ from the ambient values. The fracture surface morphology of this alloy displayed strong ductile behavior with dimple features at room temperature, but some voids formed at $900{ }^{\circ} \mathrm{C}$ along the grain boundaries with significant ductility loss due to the formation of $\mathrm{Ti}_{3} \mathrm{Al}$ phase. Microstructural analysis showed that as the temperature increased, the density of retained $\beta$ grains also reduced in $\alpha$ matrix. The fatigue test showed substantial loss of fatigue life and higher crack growth rate at higher temperatures.
\end{abstract}

KEY WORDS: Extreme environment, Elevated temperature, Fracture toughness, Fatigue behavior, Ti-6Al-4V alloy.

\section{INTRODUCTION}

Advanced nuclear fusion reactors demand very rich materials with the combination of excellent thermal and mechanical properties such as high resistance to extreme heat, pressure and radiation flux, chemical inertness in extreme environments, superior high temperature strength and good thermal conductivity. Various metals and alloys have been used as structural materials including vanadium, titanium, tungsten, tantalum, molybdenum, niobium, oxide dispersion strengthened alloys, stainless steel, etc. Among them, titaniumbased alloys are addressed as promising candidate materials for extreme temperature applications especially in nuclear reactors due to their superior thermo physical properties [1-4]. More precisely, these alloys have been used in fusion reactors as structural materials for the first wall, the magnetic coil structures, and the blanket [5]. Titanium based alloys also have other promising applications like in biomedical, aerospace industries, additive manufacturing, various industrious applications [2, 6, 7]. The alloys have high strengthto-weight ratio, superior neutronics properties, better radiation damage resistance, excellent creep and fatigue strength, and low modulus of elasticity. They also have high good corrosion resistance, electrical resistivity, low thermal expansion coefficient, low residual radioactivity, good weldability and workability. Dual phase titanium alloys $(\alpha+\beta)$ possess better tolerance to hydrogen embrittlement in fusion reactors. Other features of titanium alloys are high thermal and mechanical loading capacities and a lower density than steels or vanadium alloys [2]. 
Recent research on titanium alloys have been focused on characterization of their mechanical properties by adding different alloying elements at various strain rates and temperatures to develop new alloys with superior properties that can withstand extreme environments. It has been found $[7,8]$ that the tensile strength and yield strength decreases with increasing strain rates and temperatures. The authors found that voids and cracks nucleated circularly in shear bands and create weak points at higher temperature. These voids can cause cracks to propagate that accompanied with crack tip damage.

The mechanical properties of titanium materials can be modified by adding different alloying elements. Several studies reported $[9,10]$ that alloying elements such as vanadium, chromium, aluminum, niobium, iron, and tin change the high temperature strength, toughness, and ductility. The addition of vanadium reduced the beta transition temperature. Aluminum and oxygen help to stabilize alpha phase and increase the ultimate tensile strength properties of the titanium. Iron additions are used to stabilize beta phase and improve hardenability of the alloys [11]. In ternary alloy systems, the addition of aluminum, tin, niobium as a third element can increase the strength of the alloy and enhance the practical applications for the blanket and first wall in fusion reactors.

The tensile strength and fracture toughness of titanium alloys are also subjected to radiation exposure. Rodchenkov et al. [12] reported the neutron irradiation at $20{ }^{\circ} \mathrm{C}$ and $260{ }^{\circ} \mathrm{C}$ on Ti-V-Al ternary alloys and results showed that the reduction in fracture toughness and ductility and increase in strength. The author reported that strain hardening capability and ductility is reduced due to irradiation embrittlement. The effect of irradiation is less significant at lower temperatures. For the fatigue life test, they found minor deterioration after irradiation.

The current research focuses on the effect of environmental temperature (exposure for 2 hours) on the mechanical properties, fracture resistance, and fatigue crack growth rate of a dual phase Ti-6Al-4V.

\section{MATERIALS AND EXPERIMENTAL}

In this study, the material was a Ti-6Al-4V alloy with $0.81 \mathrm{~mm}$ and $3.2 \mathrm{~mm}$ thick sheets, manufactured by President Titanium, Hanson, MA, 6/4 GR-5. The thinner material was used for tensile and fracture toughness tests, while the thicker material was used for the fatigue crack propagation tests. The material has the following composition; Ti-89\%, V-3.98\%, Al-6.3\%, Fe-0.14\% and negligible traces of other elements.

In order to determine the difference in strength, fracture toughness, and fatigue crack growth rate of the alloy at different environmental temperatures, the specimens were exposed to some thermal history before the mechanical testing. Thus, base materials were heated in a vacuum oven (Thermo Scientific ${ }^{\mathrm{TM}}$ Lindberg/Blue $\mathrm{M}^{\mathrm{TM}}$ ) at temperatures of $650{ }^{\circ} \mathrm{C}$ and $900{ }^{\circ} \mathrm{C}$, at a heating rate of $5{ }^{\circ} \mathrm{C}$ per min with dwell time of 2 hours, and subsequent cooled down to ambient environment at a rate of $1{ }^{\circ} \mathrm{C}$ per min. The tensile experiments were performed at an ambient temperature using displacement control conditions using an MTS SINTECH 5/D material testing system facilitated with a load cell of $5000 \mathrm{lb}$. and crosshead speed of $12.5 \mathrm{~mm}$ per min. The tensile test results of the unnotched and notched specimens were used to calculate the ultimate strength and fracture toughness, respectively. The notched samples had a crack length to width ratio of 0.5 ; the gage length was $50 \mathrm{~mm}$. The fracture surface morphology of the Ti-6Al-4V after failure under static loadings was conducted using a Hitachi S-3400N SEM operated at $15 \mathrm{kV}$ acceleration voltage. The image processing software "Quartz PCI version 3.01" was used to capture the micrographs with at a range of magnifications. For optical microstructure studies, the sample from each group was polished and then metallographic etchant (Keller's reagent $95 \%$ DI water, $5 \% \mathrm{HNO}_{3}, 1.5 \% \mathrm{HCl}$, and $1 \% \mathrm{HF}$ ) was used to reveal the microstructures. The sample geometry used for static tensile tests is shown in Fig. 1. 
TFEC-2020-32409
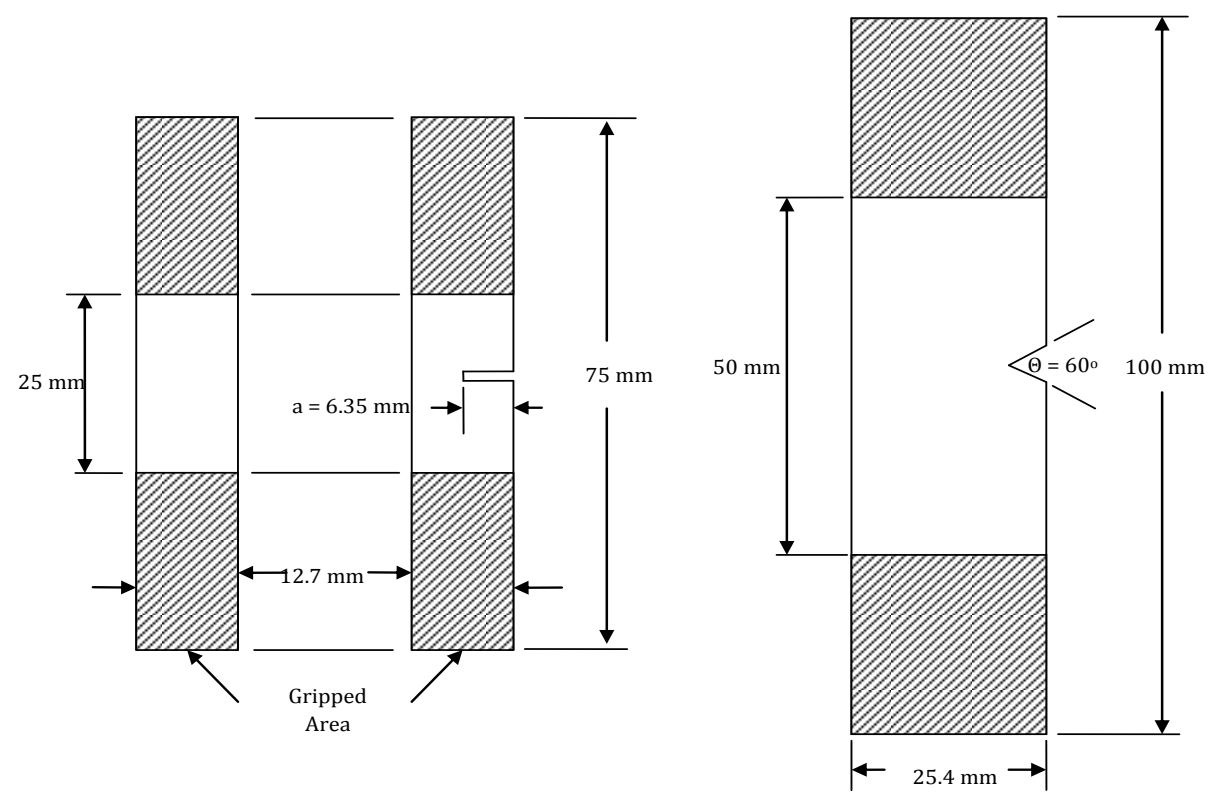

Fig. 1 Tensile specimen $(0.81 \mathrm{~mm}$ thick), showing the dimensions for both unnotched and single edge notched specimen (left), fatigue test specimen ( $3.2 \mathrm{~mm}$ thick) geometry (right).

The fatigue experiments were conducted at ambient environment using a servo hydraulic MTS 810 material testing system (Fig. 2). The instrument was facilitated with a load cell of $100 \mathrm{kN}$ and managed with MTS TestStar II software. The thickness of the fatigue specimens was $3.2 \mathrm{~mm}$, the width was $25.4 \mathrm{~mm}$ with a gage length of $50 \mathrm{~mm}$, and the notch depth was $2.3 \mathrm{~mm}$. All fatigue experiments were performed under sinusoidal cyclic load with maximum stress of $112 \mathrm{MPa}$ and a frequency of $1 \mathrm{~Hz}$. The minimum to maximum stress ratio was maintained to 0.1 . The number of cycles and crack length were monitored using a video camera setup magnified 100 times and the camera was connected to a WV-5470 monitor. The average data was collected from three samples.

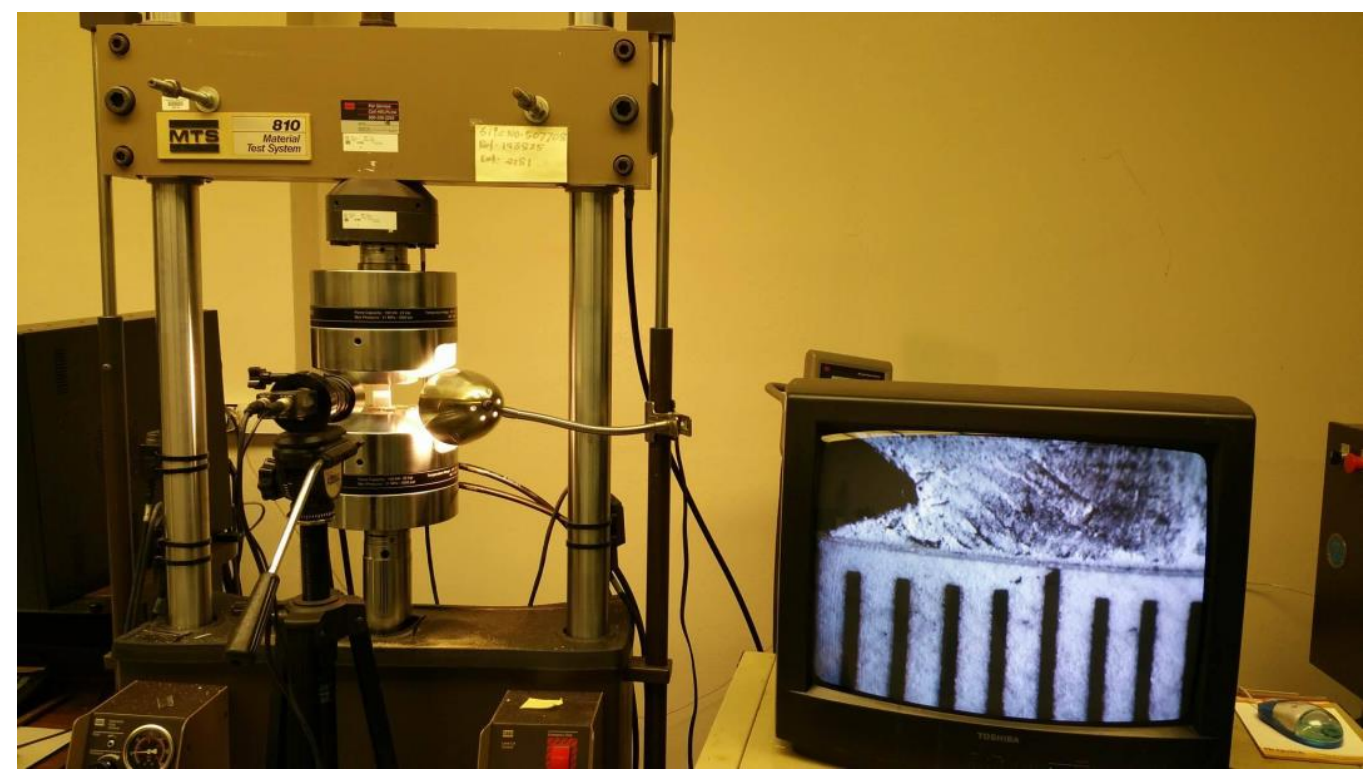

Fig. 2 A servo hydraulic material testing system (MTS 810) was used for the fatigue tests. 


\section{RESULTS AND DISCUSSION}

Static Tensile Stress-Strain Behavior: The tensile stress-strain curve of the Ti-6Al-4V for unnotched specimens as a function of environmental temperature is shown in Fig. 3. The average ultimate strength, yield strength and strain to failure at room temperature are approximately $1145 \mathrm{MPa}, 1105 \mathrm{MPa}$, and $16.7 \%$, respectively. The mechanical properties remained almost constant up to $650{ }^{\circ} \mathrm{C}$ exposure for two hours. The tensile strength and strain to failure was fallen by $\sim 24 \%$ and $89 \%$, respectively after $900{ }^{\circ} \mathrm{C}$ exposure for 2 hours.

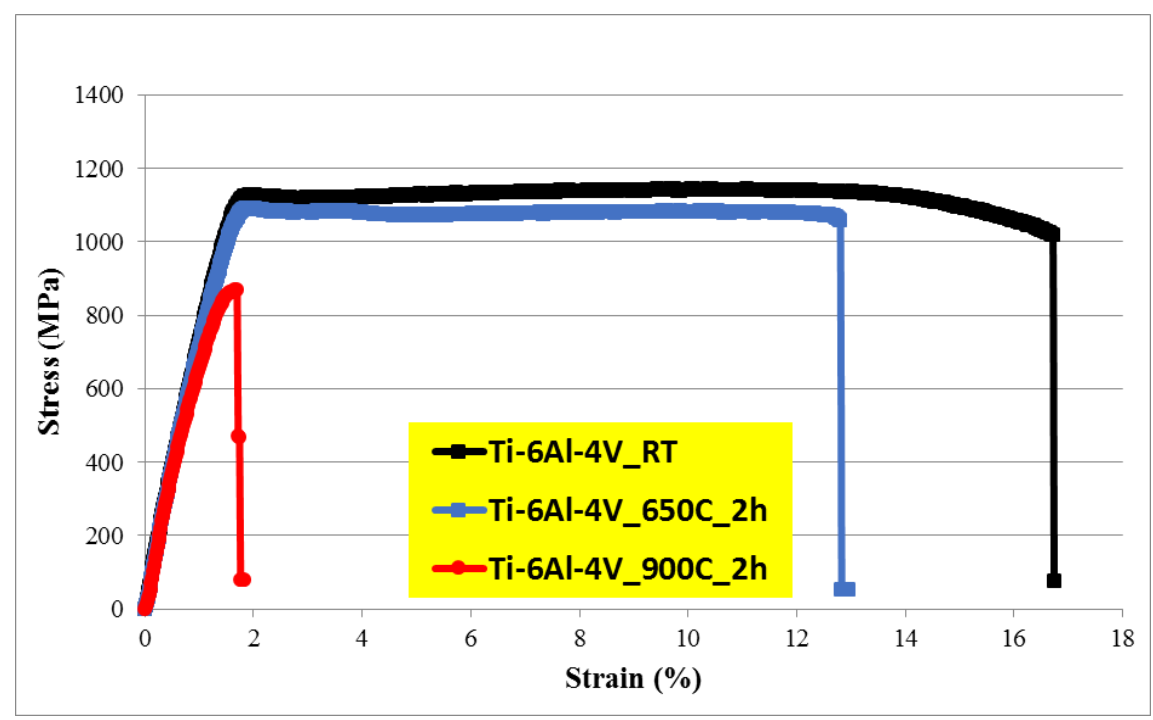

Fig. 3 Tensile strength-strain relationships of Ti-6Al-4V for unnotched specimens after exposure ( 2 hours) to different elevated environmental temperatures.

The static tensile tests were also carried out on single edge notched Ti-6Al-4V samples at different environmental temperatures. The average residual strength versus strain was plotted in Fig. 4 as a function of environmental temperature. The residual strength and strain to failure were affected very little after the $650{ }^{\circ} \mathrm{C}$ exposure for 2 hours. The average residual strength of the room temperature, $650{ }^{\circ} \mathrm{C}$, and $900{ }^{\circ} \mathrm{C}$ specimens are $511 \mathrm{MPa}, 486 \mathrm{MPa}$, and $299 \mathrm{MPa}$, respectively. The tensile strength and strain to failure was fallen significantly after $900{ }^{\circ} \mathrm{C}$ test temperature by $42 \%$ and $73 \%$, respectively.

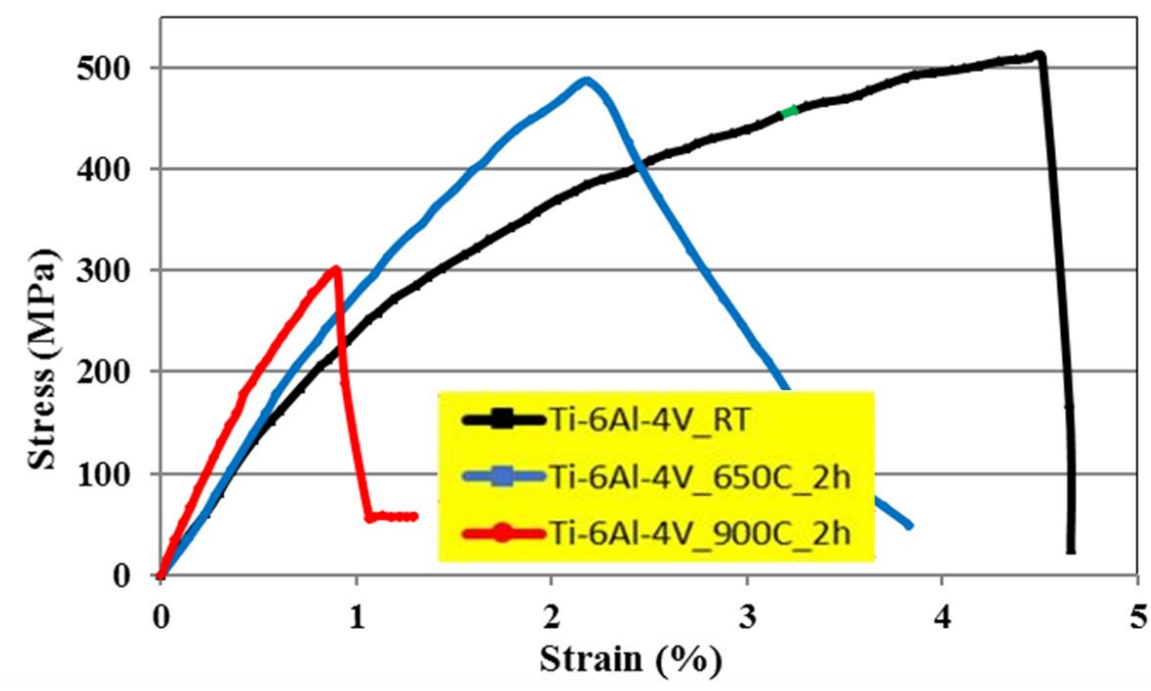

Fig. 4 Residual strength-strain relationships of Ti-6Al-4V for single edge notched specimens after exposure to different elevated environmental temperatures. 
Fracture Resistance Behavior: The fracture resistance of the specimens was calculated using the maximum stress acquired from the tested notched specimen and is given by following fracture toughness formula [13]:

$$
K_{I}=\sigma \sqrt{ } \pi a \cdot F(\alpha), \alpha=a / W
$$

Here, $\mathrm{F}(\alpha)=$ the geometric correction factor

$$
F(\alpha)=1.12-0.231 \alpha+10.55 \alpha^{2}-21.72 \alpha^{3}+30.39 \alpha^{4}
$$

$\mathrm{W}=$ Width of specimen; $\mathrm{a}=$ total crack length; $K I=$ stress intensity factor

These following conditions, as outlines by ASTM E399, are then validated to confirm the estimated fracture toughness value [1].

$$
\begin{gathered}
(W-a), \text { a and } B \geq 2.5\left(K_{Q} / \sigma_{y}\right)^{2} \\
P_{\max } / P_{Q}<1.1
\end{gathered}
$$

The average fracture toughness $\left(K_{I}\right)$ value obtained for the room temperature specimens was $180 \mathrm{MPa} \sqrt{\mathrm{m}}$, while the average $K_{I}$ value of the $650{ }^{\circ} \mathrm{C}$ and $900{ }^{\circ} \mathrm{C}$ specimens was about $175 \mathrm{MPa} \sqrt{\mathrm{m}}$ and $106 \mathrm{MPa} \sqrt{\mathrm{m}}$, respectively (Fig. 4). There is no significant difference between the room temperature and the $650^{\circ} \mathrm{C}$ samples; however, there is a $40 \%$ decrease from their room temperature values. It was also found that the calculated value for $K_{I}$ represents a plane stress conditions and not a valid $K_{I C}$ as outlined in ASTM E399. The detailed data of all the three tested specimens are given in Table 1.

Table 1. Average fracture resistance data of Ti-6Al-4V at different temperatures of room temperature, $650{ }^{\circ} \mathrm{C}$, and $900{ }^{\circ} \mathrm{C}$.

\begin{tabular}{|c|c|c|c|c|c|c|c|c|c|}
\hline Specimen & $\begin{array}{c}\mathrm{W} \\
(\mathrm{mm})\end{array}$ & $\mathrm{B}(\mathrm{mm})$ & $\mathrm{a}(\mathrm{mm})$ & $\mathrm{a} / \mathrm{W}$ & $\mathrm{F}(\mathrm{a} / \mathrm{W})$ & $\begin{array}{c}\mathrm{Pm} \\
(\mathrm{kN})\end{array}$ & $\begin{array}{c}K_{\mathrm{I}} \\
(\mathrm{MPa} \sqrt{\mathrm{m}})\end{array}$ & $\begin{array}{c}\text { Residual Strength } \\
(\mathrm{MPa})\end{array}$ & $\varepsilon(\%)$ \\
\hline $\mathrm{S}-25^{\circ} \mathrm{C}$ & 11.16 & 0.83 & 5.43 & 0.49 & 2.71 & 4.74 & 174.88 & 511.48 & 4.66 \\
\hline $\mathrm{S}-650^{\circ} \mathrm{C}$ & 12.7 & 0.81 & 6.5 & 0.51 & 2.94 & 5.00 & 180.47 & 486.13 & 3.82 \\
\hline $\mathrm{S}-900^{\circ} \mathrm{C}$ & 4.08 & 0.81 & 7.01 & 0.50 & 2.81 & 3.42 & 106.36 & 299.95 & 1.30 \\
\hline
\end{tabular}

Where, $\mathrm{W}=$ width of specimen; $\mathrm{B}=$ thickness; $\mathrm{a}=$ total crack length; $\varepsilon=$ failure strain; $K_{I}=$ fracture toughness.

Fatigue Crack Growth Kinetics ofTi-6Al-4V and Fatigue lifetime: The fatigue crack growth kinetics of Ti-6Al$4 \mathrm{~V}$ at different environmental temperatures provide a good understanding of the behavior of material under cyclic loading and hence its durability in service. From the experimental data, the crack length (a) and number of cycles $(\mathrm{N})$ for the Ti-6Al-4V alloy was plotted, as shown in Fig. 5, for both room temperature and $900{ }^{\circ} \mathrm{C}$. Both samples were tested under the same maximum applied stress of $112 \mathrm{MPa}$ and frequency of $1 \mathrm{~Hz}$, which makes the results comparable. The notch depth was around $2.3 \mathrm{~mm}$ for both samples. It can be noticed from the Fig. 5 that the total number of cycles or fatigue lifetimes of the Ti-6Al-4V alloy at room temperature is much higher than that for the elevated temperature. The average fatigue lifetime of the room temperature and the elevated temperature are about 33,000 cycles and 4800 cycles, respectively. The fatigue lifetime has two stages, initiation and propagation. The initiation lifetime for both the room temperature and $900{ }^{\circ} \mathrm{C}$ samples is about 27,000 cycles and 2300 cycles, respectively. The crack propagation lifetime is about 6,000 cycles and 2500 cycles, respectively. The crack growth observed from the tested samples shows that the crack grew slowly to about 10 $\mathrm{mm}$ after the initiation stage and propagated very quickly during last several hundred cycles. 


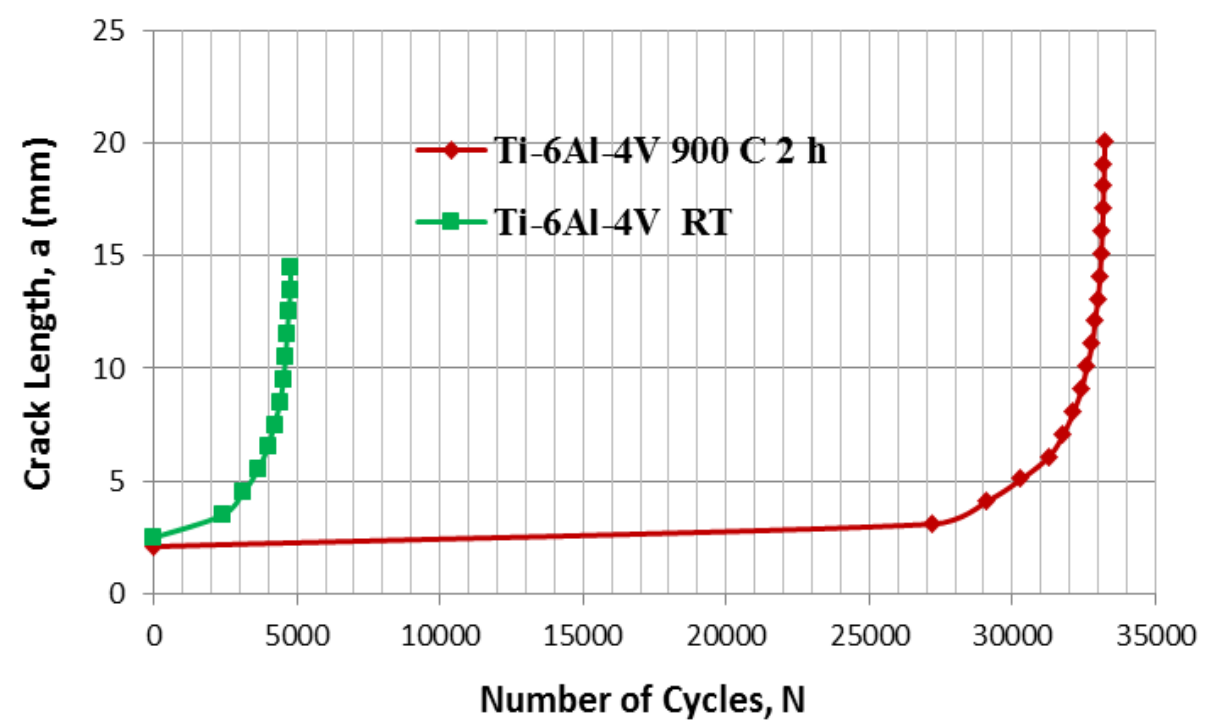

Fig. 5 Fatigue crack length, a, versus number of cycles, N.

Crack Growth Rate: The crack growth rate, da/dN, was calculated from the slope of those curves in Fig. 5 at all crack length points. The crack growth rate, da/dN, versus crack length, a, was then plotted in Fig. 6 for both samples. Sigmoidal features can be noticed from Fig. 6, demonstrating clear crack growth kinetics with growth rate, da/dN, increasing with respect to the crack length. The crack growth rate for the elevated temperature sample was higher than for the room temperature sample. This crack growth curve can be separated into three major stages. The beginning stage is called the crack initiation and spreads the crack from the initial crack length of $4.5 \mathrm{~mm}$ for both samples. Once the crack initiates, then the crack propagates in a slow and stable manner in the second stage due to microstructural and damage evolution process. In the last stage, fast and unstable crack growth kinetics was noticed. The entire crack propagation range for room temperature and $900{ }^{\circ} \mathrm{C} \mathrm{Ti}-6 \mathrm{Al}-4 \mathrm{~V}$ in all the stages was from $3 \times 10^{-7} \mathrm{~m} /$ cycle to $4.5 \times 10^{-4} \mathrm{~m} /$ cycle and $6.5 \times 10^{-7} \mathrm{~m} /$ cycle to $7.5 \times 10^{-5} \mathrm{~m} /$ cycle, respectively.

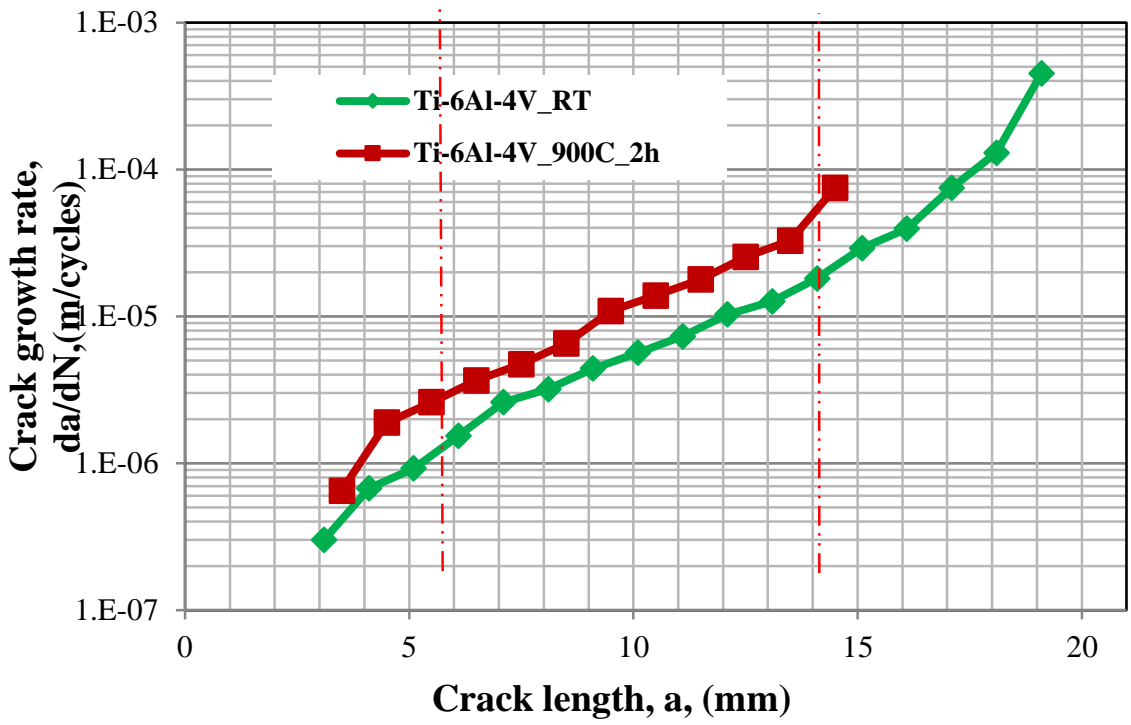

Fig. 6 Fatigue crack growth rate, da/dN, versus crack length, a.

Crack Growth Kinetics-Fracture Toughness Relationship: The relationship of fatigue crack growth rate, $\mathrm{da} / \mathrm{dN}$, versus the fracture toughness, $\Delta \mathrm{K}$, is shown in Fig. 7. The value of $\Delta \mathrm{K}$ is the difference between the stress intensity factor at the maximum applied stress of $112 \mathrm{MPa}$ and the minimum applied stress at $11.2 \mathrm{MPa}$. It can be observed from the figure that all the samples display a sigmoidal shaped crack growth behavior that 
corresponds to the three distinctive stages of the crack growth: initiation of preexisting crack (stage I), stable propagation (stage II), and failure stage or unstable growth regions (stage III). This indicates that during stage II, materials have gone through microstructural evolution and damage at crack tip during fatigue processes. The accumulation of damage within the active zone deaccelerates the process. The sample after $900{ }^{\circ} \mathrm{C}$ exposure, showed a higher crack growth rate and less fracture toughness properties. The average fracture toughness of the room temperature and $900{ }^{\circ} \mathrm{C}$ samples is about $20 \mathrm{MPa} \cdot \mathrm{m}^{1 / 2}$, and $8.5 \mathrm{MPa} \cdot \mathrm{m}^{1 / 2}$, respectively. The oxidation and void formation at higher temperature may have influenced the reduction of toughness of the material that has been seen in fracture morphology.

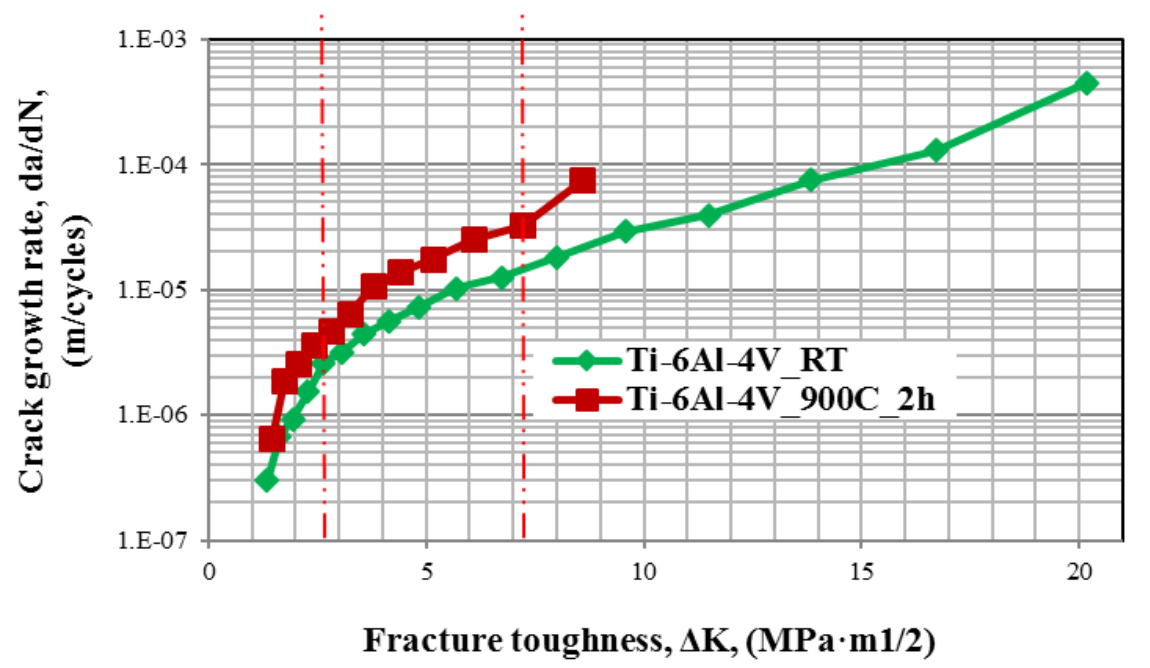

Fig. 7 Crack growth rate versus fracture toughness, $\Delta K$.

Microstructure and fracture surface morphology: At room temperature (Fig. 8a), the optical micrograph of the Ti-6Al-4V alloy displayed an irregular distribution of alpha and beta equiaxed structure. The alpha $(\alpha)$ phases, as shown in Fig. 8a white arrow, are distributed in the matrix and beta $(\beta)$ phase (red arrow in Fig. 8a) are elongated band structure with a width of $0.5-1 \mu \mathrm{m}$ and length of $2-5 \mu \mathrm{m}$. A coherent ordered $\alpha$ - structure ( $\mathrm{Ti}_{3} \mathrm{Al}$ ) was generated by alpha-phase stabilizing element (aluminum) to enhance the strength of structure. Similarly, the beta ( $\beta$ ) phase was stabilized by the alloying element (vanadium) which disperse in the structure [14]. The estimated amount of beta phase was approximately $37 \%$ at ambient temperature. Similar features were observed in the optical microstructure after aging at $650{ }^{\circ} \mathrm{C}$ for 2 hours (Fig. 8b). 

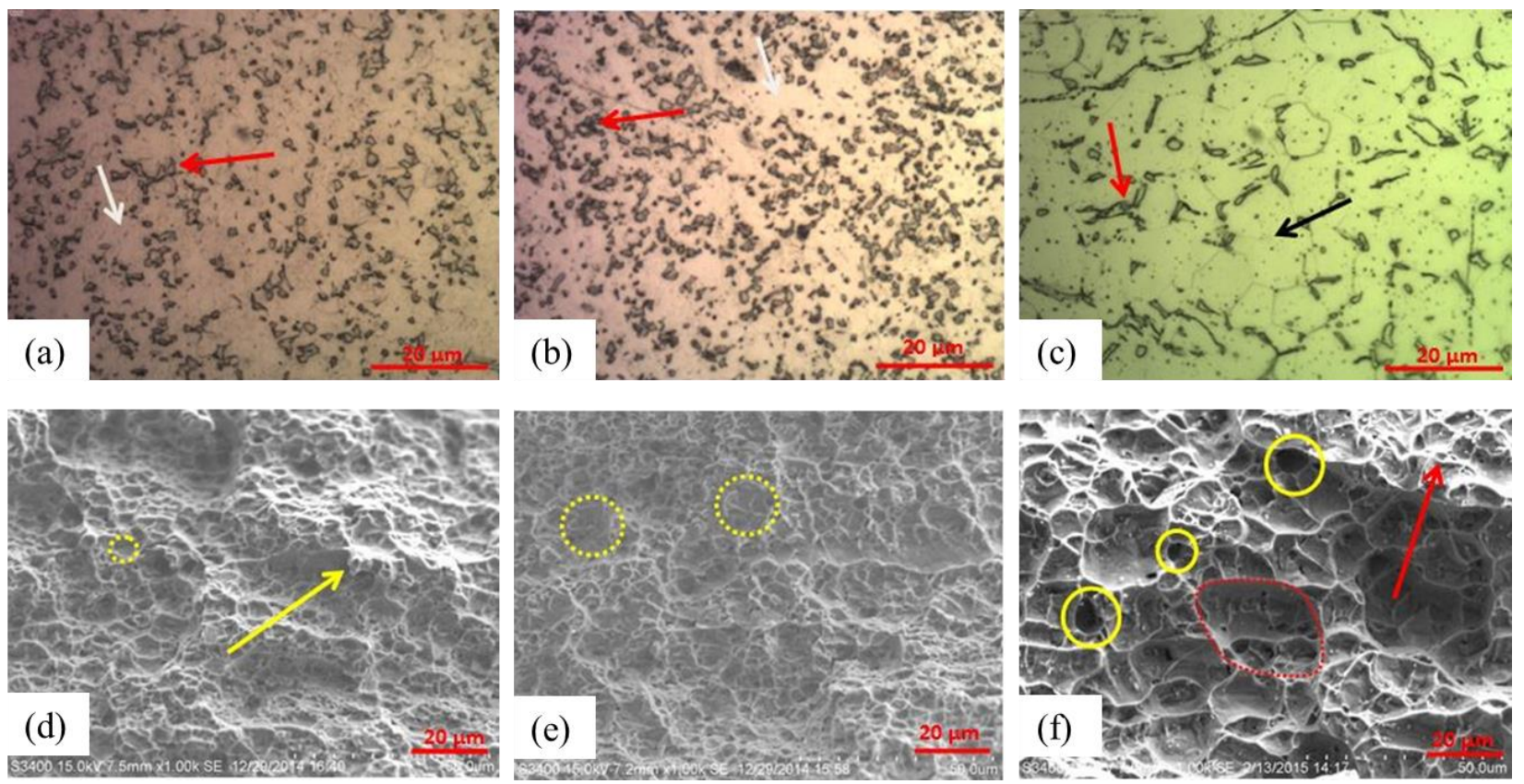

Fig. 8 Optical and SEM micrographs of the dual phase Ti-6Al-4V alloy at (a, d) room temperature, (b, e) 650 ${ }^{\circ} \mathrm{C}$, and $(\mathrm{c}, \mathrm{f}) 900{ }^{\circ} \mathrm{C}$ at $50 \mathrm{X}$, and $1000 \mathrm{X}$ magnification, respectively.

The optical micrograph of the Ti-6Al-4V alloy after exposure to $900{ }^{\circ} \mathrm{C}$ for 2 hours (Fig. 8c) revealed the transformation of $\beta$ grains to $\alpha$ - structure $\left(\mathrm{Ti}_{3} \mathrm{Al}\right)$. Moreover, partial phase transformation of hexagonal closed pack (HCP) structure to body centered cubic (BCC) crystal structure was observed. At this temperature, acicular shaped $\beta$ structure was formed with a width of 0.05-1 $\mu \mathrm{m}$ and length of 5-10 $\mu \mathrm{m}$ (red arrow in Fig. 8c). The estimated amount of beta ( $\beta$ ) phase was reduced significantly to approximately $10 \%$. Due to the formation of $\alpha$ grains from $\beta$ phase increased, the alloy also lost ductility which was also predicted by Wang et al. [15].

The fracture surface morphology at room temperature (Fig. 8d) and $650{ }^{\circ} \mathrm{C}$ (Fig. 8e) displayed similar cup and cone shaped dimple like ductile features. The calculated dimple size was approximately 3-6 $\mu \mathrm{m}$ at these temperatures. But the dimple size was also significantly increased after increasing temperature as shown in Fig. 8f. The calculated dimple size after aging at $900{ }^{\circ} \mathrm{C}$ was around $30-40 \mu \mathrm{m}$. At this higher temperature, some voids (yellow circle in Fig. 8f) and brittle cleavage (red arrow in Fig. 8f) features were also observed [14].

\section{CONCLUSIONS}

The mechanical behavior of the Ti-6Al-4V was well-explained by ductile fracture features and plasticity process as revealed on the fracture surface. The tensile strength, yield strength and strain to failure were reduced significantly at an elevated temperature exposure at $900{ }^{\circ} \mathrm{C}$ for 2 hours. At temperature of $650{ }^{\circ} \mathrm{C}$, the mechanical properties were almost similar to the room temperature ones. Similarly, the fracture toughness of the alloy at elevated temperatures was much lower than that of the parent specimen.

Fatigue crack growth of this alloy displayed the S-shape curve with three stages of crack growth kinetics. These stages included crack initiation, stable, and unstable crack growth. The fatigue resistance of this alloy at elevated temperature showed significantly lower fatigue life and higher crack growth rate than at room temperature.

The fracture surface of this alloy at elevated temperature shows some voids, large dimples, and some limited cleavage features that may contribute to the faster fatigue damage and ductility loss. However, for room temperature and $650{ }^{\circ} \mathrm{C}$, the materials show cup like dimples and pulled up strips as ductile features.

\section{ACKNOWLEDGMENT}


This project was funded by National Science Foundation (NSF) under the Partnerships for International Research and Education (PIRE) program.

\section{REFERENCES}

[1] Aglan, H., Gan, Y. X., Chin, B., \& Grossbeck, M., "Fatigue failure analysis of V-4Ti-4Cr alloy. Journal of nuclear materials," 273(2), pp. 192-202 (1999).

[2] Victoria, M., Baluc, N., and Spätig, P., "Structural materials for fusion reactors,” Nuclear Fusion, 41, pp. 1047-1053 (2001).

[3] Gurrappa, I., "Characterization of titanium alloy Ti-6Al-4V for chemical, marine and industrial applications," Material Characterization, 51, pp. 131-139 (2003).

[4] Ettefagh, A. H., Wen, H., Chaichi, A., Islam, M. I., Lu, F., Gartia, M., \& Guo, S., "Laser surface modifications of Fe-14Cr ferritic alloy for improved corrosion performance.” Surface and Coatings Technology, 125194. (2019)

[5] Marmy, P., Leguey, T., Belianov, I., and Victoria, M., "Tensile and fatigue properties of two titanium alloys as candidate materials for fusion reactors.” Journal of Nuclear Materials, 283, pp. 602-606 (2000).

[6] Yao, Hong, Ryan Katona, Jianren Zhou, Md I. Islam, Jonathan Raush, Fengyuan Lu, and Shengmin Guo. "Defects Evaluation of Selective Laser Melting Stainless Steel 316 Parts Using Positron Annihilation Lifetime Measurement," In ASME 2018 International Mechanical Engineering Congress and Exposition, pp. V08BT10A057-V08BT10A057, American Society of Mechanical Engineers (2018).

[7] Lütjering, G., and Williams, J.C., “Titanium,” (Berlin: Springer), pp. 15-52 (2003).

[8] Lee, W.S., and Lin, C.F., "Plastic deformation and fracture behavior of Ti-6Al-4V alloy loaded with high strain rate under various temperatures," Mater. Sci. Eng. A., 241, pp. 48-59 (1998).

[9] Li, M.Q., Zhang, W., "Effect of hydrogenation content on high temperature deformation behavior of Ti-6Al-4V alloy in isothermal compression,” Int. J. Hydrogen Energy., 33, pp. 2714-2720 (2008).

[10] Shan, D. B., Zong, Y. Y., Lv, Y., and Guo, B., "The effect of hydrogen on the strengthening and softening of Ti-6Al-4V alloy." Scripta materialia 58, no. 6, pp. 449-452 (2008).

[11] Srivatsan, T. S., Kuruvilla, M., \& Park, L., "A study at understanding the mechanisms governing the high cycle fatigue and final fracture behavior of the titanium alloy: Ti-4Al-2.5 V." Materials Science and Engineering: A, 527(3), pp. 435-448 (2010).

[12] Rodchenkov, B. S., Kozlov, A. V., Kuznetsov, Yu G., Kalinin, G. M., and Strebkov, Yu S., "Irradiation behavior of Ti-4Al2V (ПТ-3B) alloy for ITER blanket modules flexible attachment." Journal of Nuclear Materials 367, pp. 1312-1315 (2007).

[13] Murakami, Y., "Stress Intensity Factor Handbook," Oxford: Pergamon Press (1990).

[14] Islam, M., Fermin, C., and Aglan, H., "Microscopic Origin of Strength and Microhardness of Titanium Alloy at Elevated Temperature." Microscopy and Microanalysis, 21, S3, pp. 287-288 (2015).

[15] Wang, S. H., Wei, M. D., and Tsay, L. W., "Tensile properties of LBW welds in Ti-6Al-4V alloy at evaluated temperatures below 450 C." Materials Letters 57, no. 12, pp. 1815-1823 (2003). 